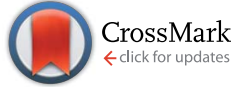

Cite this: J. Mater. Chem. A, 2015, 3, 22183

Received 23rd July 2015

Accepted 21st September 2015

DOI: $10.1039 / \mathrm{c} 5 \mathrm{ta0} 5657 \mathrm{~h}$

www.rsc.org/MaterialsA

\title{
A high-capacity $\mathrm{Li}\left[\mathrm{Ni}_{0.8} \mathrm{Co}_{0.06} \mathrm{Mn}_{0.14}\right]_{2}$ positive electrode with a dual concentration gradient for next-generation lithium-ion batteries $\uparrow$
}

\author{
Kang-Joon Park, ${ }^{a}$ Byung-Beom Lim, ${ }^{a}$ Moon-Ho Choi, ${ }^{a}$ Hun-Gi Jung, \\ Yang-Kook Sun, ${ }^{* a}$ Marta Haro, ${ }^{c}$ Nuria Vicente, ${ }^{c}$ Juan Bisquert ${ }^{c d}$ and Germà Garcia- \\ Belmonte*c
}

\begin{abstract}
To increase the reversible capacity of layered lithium nickel-cobalt-manganese oxide, a $\mathrm{Li}$ $\left[\mathrm{Ni}_{0.8} \mathrm{CO}_{0.06} \mathrm{Mn}_{0.14}\right]_{2}$ positive electrode with a two-sloped full concentration gradient (TSFCG) was successfully synthesized via co-precipitation. The TSFCG maximizes the Ni concentration in the particle core and the $\mathrm{Mn}$ concentration on the particle surface. The TSFCG $\mathrm{Li}\left[\mathrm{Ni}_{0.8} \mathrm{CO}_{0.06} \mathrm{Mn}_{0.14}\right]_{2}$ positive electrode showed improved overall electrochemical properties (i.e., reversible capacity, cycle life, and rate capability) and thermal stability compared to a conventional positive electrode (CC) $\mathrm{Li}$ $\left[\mathrm{Ni}_{0.8} \mathrm{CO}_{0.06} \mathrm{Mn}_{0.14}\right]_{2}$ without a concentration gradient. Electrochemical impedance spectroscopy showed that the high stability of the outer surface composition of $\mathrm{Li}\left[\mathrm{Ni}_{0.64} \mathrm{CO}_{0.06} \mathrm{Mn}_{0.30}\right] \mathrm{O}_{2}$ is responsible for reduction in surface resistance and charge transfer resistance by decreasing the parasitic reaction with the electrolyte. These reduced resistances explain the superior rate capability of TSFCG positive electrodes.
\end{abstract}

\section{Introduction}

Lithium-ion batteries (LIBs) have become a major power source for portable electronic devices, electric vehicles (EVs), and efficient energy storage systems (ESSs) due to their high energy density and outstanding cycle life. However, further increase in energy density and safety is essential for wider use of LIBs. The electrochemical performance, including energy density, cycle life, and safety, is strongly dependent on the two electrochemically active main components, i.e., the positive electrode and negative electrode. The deployment of new positive electrode materials with both high capacity and good safety is essential for next-generation LIBs because a layered $\mathrm{Li}\left[\mathrm{Ni}_{1-x-y} \mathrm{Co}_{x} \mathrm{Mn}_{y}\right] \mathrm{O}_{2}$ $(1-x-y=1)$ positive electrode material usually delivers a capacity of only $170 \mathrm{~mA} \mathrm{~h} \mathrm{~g}{ }^{-1}$, while graphite shows a higher capacity of $360 \mathrm{~mA} \mathrm{~h} \mathrm{~g}^{-\mathbf{1}} \mathbf{. 1 , 2}$ It is well-known that an increase in the $\mathrm{Ni}$ content of $\mathrm{Li}\left[\mathrm{Ni}_{1-x-y} \mathrm{Co}_{x} \mathrm{Mn}_{y}\right] \mathrm{O}_{2}$ leads to an increase in capacity, but the resulting capacity retention and safety slowly ${ }^{a}$ Department of Energy Engineering, Hanyang University, Seoul 133-791, South Korea.
E-mail: yksun@hanyang.ac.kr
${ }^{b}$ Center for Energy Convergence, Korea Institute of Science and Technology, Seoul 136-
791, South Korea

'Institute of Advanced Materials (INAM), Universitat Jaume I, ES-12071 Castelló, Spain.E-mail: garciag@uji.es

${ }^{d}$ Department of Chemistry, Faculty of Science, King Abdulaziz University, Jeddah 21589, Saudi Arabia

$\dagger$ Electronic supplementary information (ESI) available. See DOI: $10.1039 / \mathrm{c} 5 \mathrm{ta} 05657 \mathrm{~h}$ decrease. ${ }^{3-7}$ Among the layered $\mathrm{Li}\left[\mathrm{Ni}_{1-x-y} \mathrm{Co}_{x} \mathrm{Mn}_{y}\right] \mathrm{O}_{2}$ materials, $\mathrm{Li}\left[\mathrm{Ni}_{0.8} \mathrm{Co}_{0.1} \mathrm{Mn}_{0.1}\right] \mathrm{O}_{2}$ showed a high capacity around $200 \mathrm{~mA} \mathrm{~h}$ $\mathrm{g}^{-1}$, but the cycle life and thermal properties of the positive electrode must be further improved for use in LIBs. ${ }^{\mathbf{8 9}}$

Recently, we developed functional layered oxide materials with a core-shell (or core with gradient shell) and full concentration gradient (FCG) structure through the hybridization of $\mathrm{Ni}$-rich and $\mathrm{Ni}$-poor $\mathrm{Li}\left[\mathrm{Ni}_{1-x-y} \mathrm{Co}_{x} \mathrm{Mn}_{y}\right] \mathrm{O}_{2}$ positive electrode materials at the particle level, placing the former in the particle center and the latter on the particle surface..$^{\mathbf{1 0 - 1 2}}$ The Ni-rich core delivers high capacity, and the Mn-rich shell provides outstanding cycle life and thermal stability. Our recent studies showed a new FCG positive electrode material composed of long-rod shaped primary particles aligned toward the particle center, which exhibited improved electrochemical performance because of a smaller contact area with the electrolyte and faster $\mathrm{Li}^{+}$diffusivity resulting from a unique crystallographic texture. ${ }^{11,12}$ The proposed approach makes possible the design of various positive electrode materials with different particle centers and surface compositions by changing the concentration gradient slope. Recently, we developed a Ni-rich layered $\mathrm{Li}$ $\left[\mathrm{Ni}_{0.65} \mathrm{Co}_{0.13} \mathrm{Mn}_{0.22}\right] \mathrm{O}_{2}$ positive electrode material with a twosloped full concentration gradient (TSFCG) of Ni, Co, and Mn within a particle in order to maximize the Ni concentration in the particle core and the Mn concentration in the particle surface layer. ${ }^{13}$ The resulting material showed outstanding electrochemical performance in terms of capacity, cycle life, and thermal stability. ${ }^{13}$ 
Here, we synthesized a promising $\mathrm{Li}\left[\mathrm{Ni}_{0.8} \mathrm{Co}_{0.06} \mathrm{Mn}_{0.14}\right] \mathrm{O}_{2}$ positive electrode material targeted for $\mathrm{EV}$ applications with a TSFCG of Ni, Co, and Mn throughout the particle and reported its basic electrochemical properties. With a view toward uncovering the origin of the superior rate capability exhibited by TSFCG positive electrodes, the assembled half batteries were characterized using electrochemical impedance spectroscopy in order to discern the different steps involved in the chargedischarge process and interpret the performance in terms of a proposed equivalent model. This approach is known to facilitate the extraction of resistances involved in lithium ion storage at the electrolyte-electrode interface as well as the insertionextraction process occurring during cycling of the battery. ${ }^{\mathbf{1 4 , 1 5}}$ For comparison, we also synthesized and studied the electrochemical performance of a conventional positive electrode (CC, composition of $\mathrm{Li}\left[\mathrm{Ni}_{0.8} \mathrm{Co}_{0.06} \mathrm{Mn}_{0.14}\right] \mathrm{O}_{2}$ ) without a concentration gradient. We observed that key electrochemical mechanisms at the electrode surface largely determine the rate capability battery performance. It is noteworthy that the EIS technique can be used to decouple electrochemical processes at the electrode surface from those occurring in the particle bulk.

\section{Experimental}

\subsection{Synthesis of $\mathrm{CC} \mathrm{Li}\left[\mathrm{Ni}_{0.8} \mathrm{Co}_{0.06} \mathrm{Mn}_{0.14}\right] \mathrm{O}_{2}$}

$\mathrm{A}\left[\mathrm{Ni}_{0.8} \mathrm{Co}_{0.06} \mathrm{Mn}_{0.14}\right](\mathrm{OH})_{2}$ precursor was synthesized via coprecipitation of $\mathrm{NiSO}_{4} \cdot 6 \mathrm{H}_{2} \mathrm{O}, \mathrm{CoSO}_{4} \cdot 7 \mathrm{H}_{2} \mathrm{O}$, and $\mathrm{MnSO}_{4} \cdot 5 \mathrm{H}_{2} \mathrm{O}$ ( $80: 6: 14$ in molar ratio) as starting materials. Details of the preparation procedures are given in a previous report. ${ }^{11}$ The obtained $\left[\mathrm{Ni}_{0.8} \mathrm{Co}_{0.06} \mathrm{Mn}_{0.14}\right](\mathrm{OH})_{2}$ hydroxide precursor was mixed with $\mathrm{LiOH} \cdot \mathrm{H}_{2} \mathrm{O}$ and calcined at $740^{\circ} \mathrm{C}$ for $10 \mathrm{~h}$ in flowing oxygen.

\subsection{Synthesis of TSFCG $\mathrm{Li}\left[\mathrm{Ni}_{0.8} \mathrm{Co}_{0.06} \mathrm{Mn}_{0.14}\right] \mathrm{O}_{2}$}

To prepare the $\left[\mathrm{Ni}_{0.8} \mathrm{Co}_{0.06} \mathrm{Mn}_{0.14}\right](\mathrm{OH})_{2}$ precursor, a Ni-deficient aqueous solution ( $\mathrm{Ni}: \mathrm{Co}: \mathrm{Mn}=89: 4: 7$ in molar ratio) of $\mathrm{NiSO}_{4} \cdot 6 \mathrm{H}_{2} \mathrm{O}, \mathrm{CoSO}_{4} \cdot 7 \mathrm{H}_{2} \mathrm{O}$, and $\mathrm{MnSO}_{4} \cdot 5 \mathrm{H}_{2} \mathrm{O}$ was slowly pumped into a Ni-rich ( $\mathrm{Ni}: \mathrm{Mn}=98: 2$ in molar ratio) stock solution, after which the homogeneously mixed solution was fed into a batch reactor $(40 \mathrm{~L})$ which was filled with a certain amount of deionized water, $\mathrm{NH}_{4} \mathrm{OH}$ solution (aq.), and $\mathrm{NaOH}$ solution (aq.) in a replenished $\mathrm{N}_{2}$ atmosphere. Concurrently, a $4.0 \mathrm{~mol} \mathrm{~L}^{-1} \mathrm{NaOH}$ solution (aq.) (molar ratio of sodium hydroxide to transition metal $=2.0$ ) and the desired amount of an aqueous $\mathrm{NH}_{4} \mathrm{OH}$ solution (molar ratio of ammonium hydroxide to transition metal $=1.0$ ) were pumped separately into the reactor. During the early stage of precipitation, $\left[\mathrm{Ni}_{0.98} \mathrm{Mn}_{0.02}\right](\mathrm{OH})_{2}$ (center composition) was co-precipitated first. Nickel-cobalt-manganese hydroxides with different compositions were then slowly added to the formed $\left[\mathrm{Ni}_{0.98^{-}}\right.$ $\left.\mathrm{Mn}_{0.02}\right](\mathrm{OH})_{2}$ particles to provide the first concentration gradient of $\mathrm{Ni}, \mathrm{Co}$, and $\mathrm{Mn}$ toward the particle outer surface. To construct the second concentration gradient layer onto the TSFCG hydroxide precursor, an aqueous solution with a lower $\mathrm{Ni}$ concentration (consisting of $\mathrm{NiSO}_{4} \cdot 6 \mathrm{H}_{2} \mathrm{O}, \mathrm{CoSO}_{4} \cdot 7 \mathrm{H}_{2} \mathrm{O}$, and $\mathrm{MnSO}_{4} \cdot 5 \mathrm{H}_{2} \mathrm{O}$, molar ratio of $\left.\mathrm{Ni}: \mathrm{Co}: \mathrm{Mn}=56: 16: 28\right)$ was gradually pumped into the mixed (molar ratio of $\mathrm{Ni}: \mathrm{Co}: \mathrm{Mn}=$ $92: 4: 4)$ solution. The co-precipitated precursor powders were filtered, washed with deionized water, and dried at $110{ }^{\circ} \mathrm{C}$. The TSFCG $\left[\mathrm{Ni}_{0.8} \mathrm{Co}_{0.06} \mathrm{Mn}_{0.14}\right](\mathrm{OH})_{2}$ was mixed with $\mathrm{LiOH} \cdot \mathrm{H}_{2} \mathrm{O}$, and the mixture was calcined at $760{ }^{\circ} \mathrm{C}$ for $15 \mathrm{~h}$ in flowing oxygen.

\subsection{Material characterization}

The chemical composition of the prepared powders was determined using inductively coupled plasma (ICP, ARCOS165FHE16, SPECTRO Co.). Powder X-ray diffraction (XRD, Rint-2000, Rigaku) using $\mathrm{Cu} \mathrm{K}_{\alpha}$ radiation was used to identify the crystalline phases of the prepared powders. The morphology of the powders was observed by scanning electron microscopy (SEM, JSM 6400, JEOL). To obtain the localized composition of the materials at the particle level, cross-sections of the particles were prepared by embedding the particles in an epoxy and grinding them flat. Line scans of the polished surfaces for the prepared TSFCG hydroxide precursors and lithiated oxides were analyzed using an electron probe microanalyzer (EPMA) (JXA-8100, JEOL). For the DSC experiments, the cells containing the positive electrode materials were charged at a constant voltage of $4.3 \mathrm{~V}$ versus $\mathrm{Li}$, and disassembled in an Arfilled dry box. A $30 \mu \mathrm{L}$ high-pressure stainless-steel DSC vessel with a gold-plated copper seal was used to host 3-5 mg samples, including solids and the electrolyte. The measurements were carried out in a Pyris 1 differential scanning calorimeter (Perkin Elmer) using a scanning rate of $5{ }^{\circ} \mathrm{C} \mathrm{min}^{-1}$.

\subsection{Electrochemical test}

For the fabrication of the positive electrodes, the synthesized powders were mixed with carbon black and polyvinylidene fluoride ( $85: 7.5: 7.5$ ) in $N$-methylpyrrolidinone. The obtained slurry was coated onto an $\mathrm{Al}$ foil and roll-pressed. Preliminary cell tests were performed with a 2032 coin-type cell using $\mathrm{Li}$ metal as the counter electrode cycled at 2.7-4.3 V. The electrolyte solution was $1.2 \mathrm{M} \mathrm{LiPF}_{6}$ in ethylene carbonate-ethylmethyl carbonate ( $3: 7$ in volume). The cells were charged and discharged at $30{ }^{\circ} \mathrm{C}$ and between 3.0 and $4.3 \mathrm{~V}$ by applying a constant $0.5 \mathrm{C}$ rate $\left(105 \mathrm{~mA} \mathrm{~g}^{-1}\right)$. Cyclic voltammetry $(\mathrm{CV})$ and impedance spectroscopy (EIS) were performed using a PGSTAT30 potentiostat from Autolab equipped with an impedance module. EIS was performed at several voltages with a $10 \mathrm{mV}$ amplitude in the frequency range from $1 \mathrm{MHz}$ to $1 \mathrm{mHz}$.

\section{Results and discussion}

\subsection{Material characterization}

The total chemical composition of the as-prepared TSFCG and CC positive active materials was found to be $\mathrm{Li}\left[\mathrm{Ni}_{0.8} \mathrm{Co}_{0.06}{ }^{-}\right.$ $\left.\mathrm{Mn}_{0.14}\right] \mathrm{O}_{2}$ as determined by ICP. Fig. 1 shows the X-ray diffraction (XRD) patterns of the as-prepared TSFCG and CC Li $\left[\mathrm{Ni}_{0.8} \mathrm{Co}_{0.06} \mathrm{Mn}_{0.14}\right] \mathrm{O}_{2}$. The XRD confirmed that the two powders have a well-defined layered structure based on a hexagonal a$\mathrm{NaFeO}_{2}$ structure with space group $R \overline{3} m$ without any impurity phases. However, it is observed that the peak splitting of (006)/ (102) and (108)/(110) pairs of TSFCG becomes more clear than 


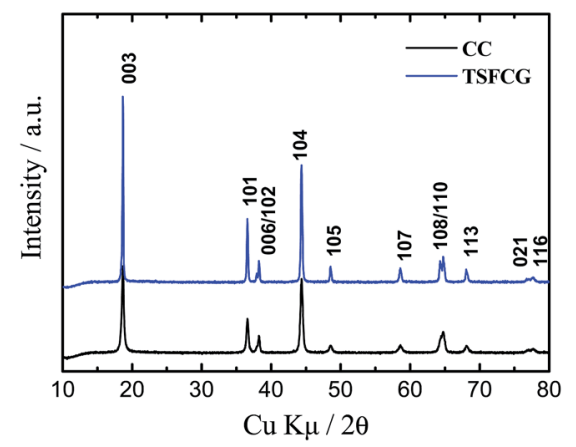

Fig. 1 Powder XRD patterns of the TSFCG and $\mathrm{CC} \mathrm{Li}\left[\mathrm{Ni}_{0.8} \mathrm{CO}_{0.06^{-}}\right.$ $\mathrm{Mn}_{0.14} \mathrm{OO}_{2}$.

that of CC, indicating development of a more-ordered layered structure.

Fig. 2 shows the compositional variations of the Ni, Co, and Mn on the cross-section of a single particle measured by using an EPMA with a probe diameter of $1 \mu \mathrm{m}$. As can be seen in Fig. 2a, the Ni concentration decreased linearly from the particle center to $4.5 \mu \mathrm{m}$ toward the particle surface and then suddenly decreased at the particle outer surface (thickness 1 $\mu \mathrm{m})$. In contrast, the Co and Mn concentrations increased steadily in the first $4.5 \mu \mathrm{m}$, and Mn concentration abruptly increased at the particle surface. The $\mathrm{Ni}$ concentration decreased gradually from $96 \%$ to $92 \%$ in the first $4.5 \mu \mathrm{m}$, whereas the Co concentration increased from $1 \%$ to $5 \%$ and the Mn concentration increased from 3\% to $4 \%$, leading to a center composition of $\left[\mathrm{Ni}_{0.96} \mathrm{Co}_{0.01} \mathrm{Mn}_{0.03}\right](\mathrm{OH})_{2}$. After the $4.5 \mu \mathrm{m}$ region (concentration gradient 1 ), the $\mathrm{Ni}$ concentration further decreased to $61 \%$ from $92 \%$ (concentration gradient 2) toward the particle surface, while Co and Mn concentrations increased rapidly to $8 \%$ and $31 \%$, respectively, resulting in a surface composition of $\left[\mathrm{Ni}_{0.61} \mathrm{Co}_{0.08} \mathrm{Mn}_{0.31}\right](\mathrm{OH})_{2}$. Interdiffusion of transition metal ions throughout the particle of the lithiated oxide had little effect on the outer surface composition during the high-temperature calcination, as can be seen in Fig. $2 \mathrm{~b}$. Though the Ni concentration in the particle center decreased from $96 \%$ to $88 \%$, the Mn concentration on the particle surface, which is crucial for cycle life and safety of the battery, decreased

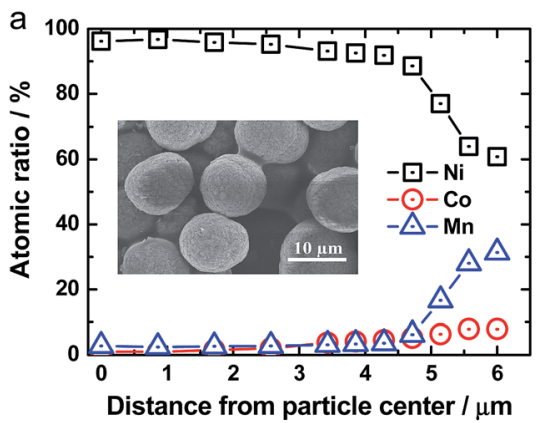

by only 1 at\%, resulting in a surface composition of $\mathrm{Li}\left[\mathrm{Ni}_{0.64^{-}}\right.$ $\left.\mathrm{Co}_{0.06} \mathrm{Mn}_{0.30}\right] \mathrm{O}_{2}$.

\subsection{Electrochemical and thermal properties}

The basic electrochemical properties of the TSFCG and CC Li $\left[\mathrm{Ni}_{0.8} \mathrm{Co}_{0.06} \mathrm{Mn}_{0.14}\right] \mathrm{O}_{2}$ positive electrode materials were tested in 2032 coin-type half-cells employing $\mathrm{Li}$ metal as the counter electrode, and the results are shown in Fig. 3. As shown in Fig. 3a, the TSFCG positive electrode delivered a high discharge capacity of $211 \mathrm{~mA} \mathrm{~h} \mathrm{~g}^{-1}$ between 2.7 and $4.3 \mathrm{~V}$ at $0.1 \mathrm{C}(21 \mathrm{~mA}$ $\left.\mathrm{g}^{-1}\right)$. In contrast, the CC positive electrode exhibited a reduced discharge capacity of $203 \mathrm{~mA} \mathrm{~h}^{-1}$. As studied in our previous work, ${ }^{11}$ the higher $\mathrm{Ni}^{2+}$ concentration in the outer surface layer of the TSFCG delivered a higher capacity because of the twoelectron redox reaction of $\mathrm{Ni}^{2+} \leftrightarrow \mathrm{Ni}^{4+}$. Fig. 3 b shows corresponding capacity retentions of TSFCG and CC positive electrodes cycled at $0.5 \mathrm{C}\left(105 \mathrm{~mA} \mathrm{~g}^{-1}\right)$. As anticipated, the TSFCG positive electrode showed a greatly improved $\mathrm{Li}^{+}$intercalation stability with a capacity retention of $94.6 \%$ after 100 cycles. In contrast, the CC positive electrode suffered from a poor cycle life, showing a capacity retention of only $79.2 \%$ after the same cycling period. It is known that the rod-shaped primary particles in the FCG positive electrode with a crystallographic texture show high-rate capability characteristics due to their unique microstructure; this structure provides a smooth $\mathrm{Li}^{+}$diffusion path without grain boundary resistance, as observed in the CC positive electrode. ${ }^{11,12}$ Fig. $3 \mathrm{c}$ shows rate capability values of the TSFCG and CC Li[ $\left[\mathrm{Ni}_{0.8} \mathrm{Co}_{0.06} \mathrm{Mn}_{0.14}\right] \mathrm{O}_{2}$ positive electrodes. Each cell was charged and discharged galvanostatically at different $\mathrm{C}$ rates ranging from $0.2 \mathrm{C}$ to $5 \mathrm{C}\left(42-1050 \mathrm{~mA} \mathrm{~g}^{-1}\right)$. As expected, the TSFCG positive electrode exhibited better rate capability performance than the CC positive electrode, especially at higher $\mathrm{C}$ rates. The capacity retention of the TSFCG positive electrode at $5 \mathrm{C}$ compared to that at $0.2 \mathrm{C}$ was $76.8 \%$, still delivering 160 $\mathrm{mA} \mathrm{h} \mathrm{g}^{-1}$, whereas the CC positive electrode showed a lower retention of $70.7 \%$ with a capacity of $139 \mathrm{~mA} \mathrm{~h} \mathrm{~g}^{-1}$.

The morphology and microstructure of recovered TSFCG powders from the disassembled 2032 coin-type half-cell after 100 cycles are shown in Fig. 4 . The spherical morphology of the secondary particle and the rod-shaped primary particle morphology (inset of Fig. 4a) are well maintained even after

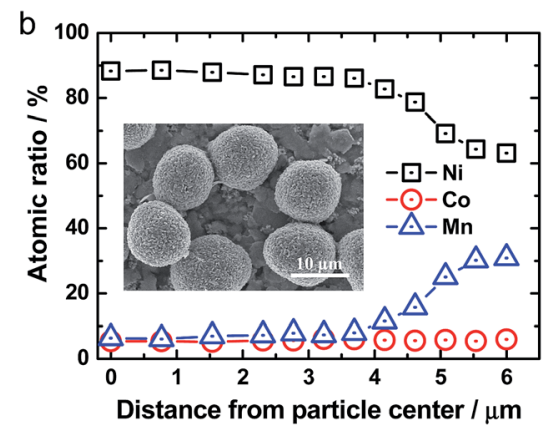

Fig. 2 EPMA and SEM results. EPMA line scan of the integrated atomic ratio of transition metals as a function of the distance from the particle center to the surface for (a) precursor and (b) lithiated positive electrode material. 

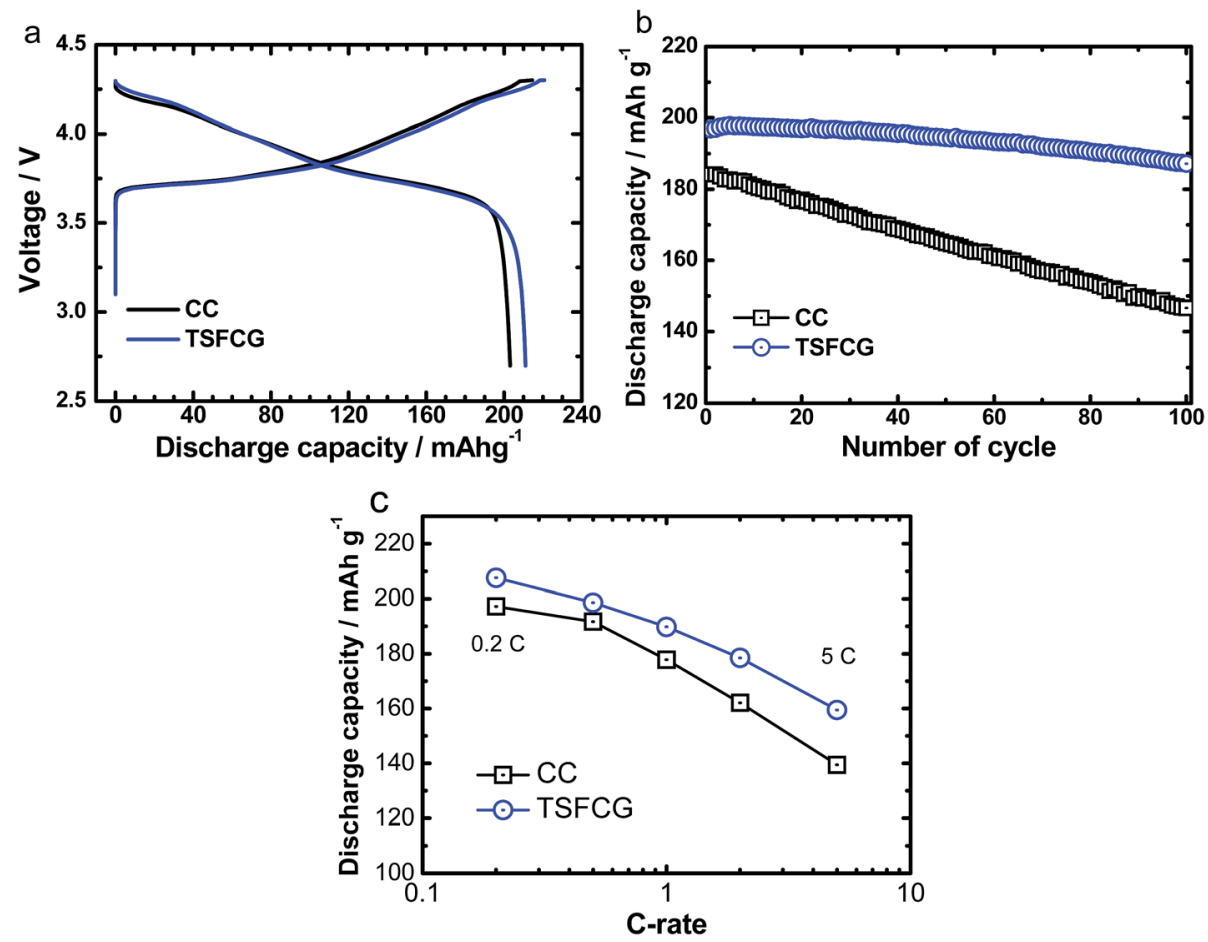

Fig. 3 Charge-discharge characteristics of CC and TSFCG Li[Ni $\left.{ }_{0.8} \mathrm{CO}_{0.06} \mathrm{Mn}_{0.14}\right]_{2} \mathrm{O}_{2}$ positive electrodes at $30{ }^{\circ} \mathrm{C}$. (a) Initial charge and discharge curves of CC and TSFCG positive electrodes obtained from a 2032 coin-type half-cell using Li metal as the counter electrode at a constant current of $1 / 10 \mathrm{C}\left(21 \mathrm{~mA} \mathrm{~g}^{-1}\right.$ ). (b) Cycling performance of half-cells using CC and TSFCG positive electrodes cycled between 2.7 and $4.3 \mathrm{~V}$ at a constant current of $\mathrm{C} / 2\left(105 \mathrm{~mA} \mathrm{~g}^{-1}\right)$. (c) Comparison of rate capabilities of the TSFCG with the CC positive electrode (upper cutoff voltage of 4.3 $\vee$ versus $\mathrm{Li}^{+} / \mathrm{Li}$ ).

long-term cycling (100 cycles) compared to pristine TSFCG powders (see the inset of Fig. 2b). The compositional change within a cycled particle was also quantitatively characterized by using the EPMA (Fig. 4b). The cycled TSFCG particle has a two slope concentration gradient, showing the decrease of $\mathrm{Ni}$ concentration and the increase of Mn concentration from the particle center toward the particle surface. The resulting center and surface compositions of the particle were $\mathrm{Li}\left[\mathrm{Ni}_{0.86} \mathrm{Co}_{0.05^{-}}\right.$ $\left.\mathrm{Mn}_{0.09}\right] \mathrm{O}_{2}$ and $\mathrm{Li}\left[\mathrm{Ni}_{0.64} \mathrm{Co}_{0.10} \mathrm{Mn}_{0.26}\right] \mathrm{O}_{2}$, respectively. From the above results, we believe that long term cycling hardly affects both the concentration gradient variation of transition metals within a particle and morphology change of the powders.
Furthermore, the specific surface area of the TSFCG powders is $0.64 \mathrm{~m}^{2} \mathrm{~g}^{-1}$, while that of $\mathrm{CC}$ is $1.49 \mathrm{~m}^{2} \mathrm{~g}^{-1}$. It is reported that a lower specific surface area of the positive-electrode material gives rise to a decreased exposed contact area with the electrolyte, leading to a reduction of transition metal dissolution by HF attack in the electrolyte and, thus improving the capacity retention of the cell. ${ }^{12}$ The lower specific surface area together with maintenance of the microstructure of the TSFCG particle improves the cycling performance.

Fig. 5 shows differential scanning calorimetry (DSC) curves of cells with the TSFCG and CC $\mathrm{Li}_{1-\delta}\left[\mathrm{Ni}_{0.8} \mathrm{Co}_{0.06} \mathrm{Mn}_{0.14}\right] \mathrm{O}_{2}$ electrodes charged to $4.3 \mathrm{~V}$ in the presence of the electrolyte.
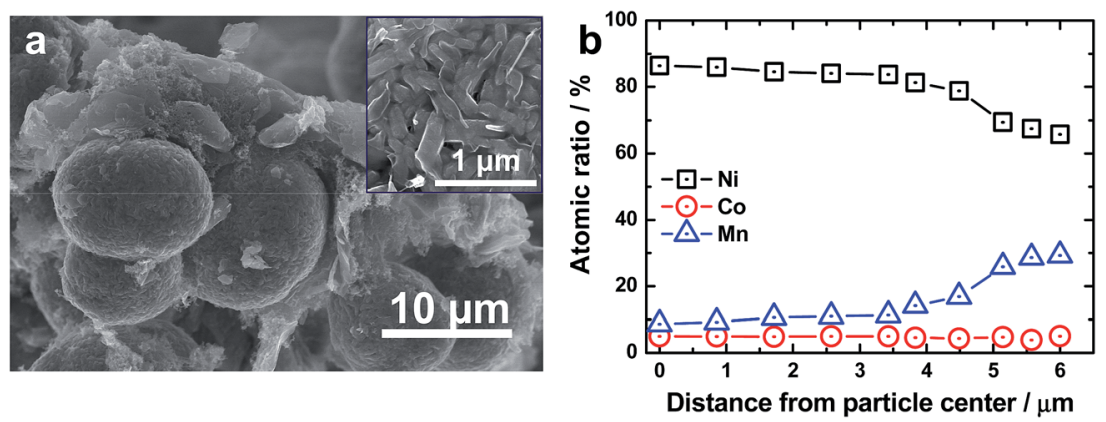

Fig. 4 (a) SEM image of TSFCG Li[Ni $\left.{ }_{0.8} \mathrm{CO}_{0.06} \mathrm{Mn}_{0.14}\right] \mathrm{O}_{2}$ powders after 100 cycles in a 2032 coin-type half-cell and magnified image of the particle in the inset and (b) EPMA line scan of the integrated atomic ratio of transition metals as a function of the distance from the particle center to the surface for the cycled TSFCG Li[Ni $\left.\mathrm{Ni}_{0.8} \mathrm{CO}_{0.06} \mathrm{Mn}_{0.14}\right] \mathrm{O}_{2}$. 


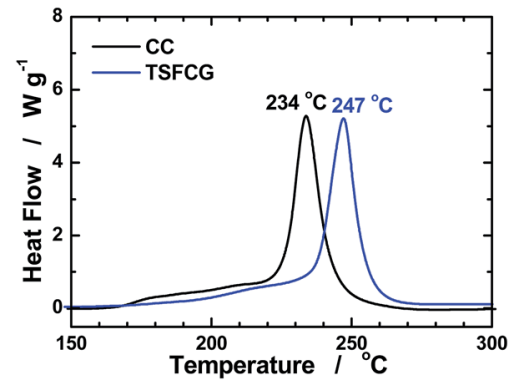

Fig. 5 DSC traces of the TSFCG and CC $\mathrm{Li}_{1-\delta}\left[\mathrm{Ni}_{0.8} \mathrm{CO}_{0.06} \mathrm{Mn}_{0.14}\right] \mathrm{O}_{2}$ electrodes.

The CC $\mathrm{Li}_{1-\delta}\left[\mathrm{Ni}_{0.8} \mathrm{Co}_{0.06} \mathrm{Mn}_{0.14}\right] \mathrm{O}_{2}$ electrode exhibited an exothermal peak at $234{ }^{\circ} \mathrm{C}$ with a heat generation of $1145 \mathrm{~J} \mathrm{~g}^{-1}$. In contrast, the TSFCG electrode shows enhanced thermal properties with an exothermic reaction peak at $247^{\circ} \mathrm{C}$ and a reduced heat generation of $991 \mathrm{~J} \mathrm{~g}^{-1}$. In accordance with the previously reported FCG positive electrodes, ${ }^{\mathbf{1 0 - 1 3 , 1 6}}$ the thermal stability of $\mathrm{Li}\left[\mathrm{Ni}_{x} \mathrm{Co}_{y} \mathrm{Mn}_{z}\right] \mathrm{O}_{2}$ gradually decreased as the $\mathrm{Ni}$ content increased. Even if the TSFCG and CC positive electrodes have the same chemical composition $\left(\mathrm{Li}\left[\mathrm{Ni}_{0.8} \mathrm{Co}_{0.06} \mathrm{Mn}_{0.14}\right] \mathrm{O}_{2}\right)$, the surface Ni composition of 0.64 in the TSFCG is lower than that of 0.8 in CC. Therefore, the improved thermal properties of the TSFCG positive electrode resulted from the higher thermal stability of the outer surface composition of $\mathrm{Li}\left[\mathrm{Ni}_{0.64} \mathrm{Co}_{0.06^{-}}\right.$ $\left.\mathrm{Mn}_{0.30}\right] \mathrm{O}_{2}$ in the TSFCG positive electrode.

\subsection{Impedance and capacitance response}

To obtain further insight into the superior rate capability and higher stability exhibited by TSFCG positive electrodes, the assembled half batteries were characterized using electrochemical impedance spectroscopy. EIS allows discernment of the kinetic limitations inferred from resistive processes occurring during the electrode operation. After three CV cycles, the EIS measurements were conducted potentiostatically at different stages of $\mathrm{Li}^{+}$ion insertion and extraction at a very low rate in order to ensure a steady state. After impedance spectroscopy experiments, another three CV cycles were performed to verify that the electrodes were not changed or damaged during EIS measurements (Fig. SI. $1 \dagger$ ). The resulting Nyquist diagrams are presented in Fig. 6.

In general, the Nyquist spectra exhibit two features with distinguishable time constants associated with specific electrochemical mechanisms, i.e., those at high frequencies, related to interfacial processes, and those at low frequencies related to the chemical energy storage/delivery mechanism. Taking into account the features of these plots and previous models described in the literature, ${ }^{\mathbf{1 7 - 1 9}}$ we propose an equivalent circuit, shown in Fig. 7, which fits the experimental data properly, as observed in the comparison between experimental data and the fitting line in Fig. 6. At high frequencies, an arc related to the resistance, $R_{\mathrm{sf}}$, and capacity, $C_{\mathrm{sf}}$, of the $\mathrm{Li}^{+}$diffusion through the solid film can be observed. It has been previously reported that solid films are formed on lithiated transition-metal oxides
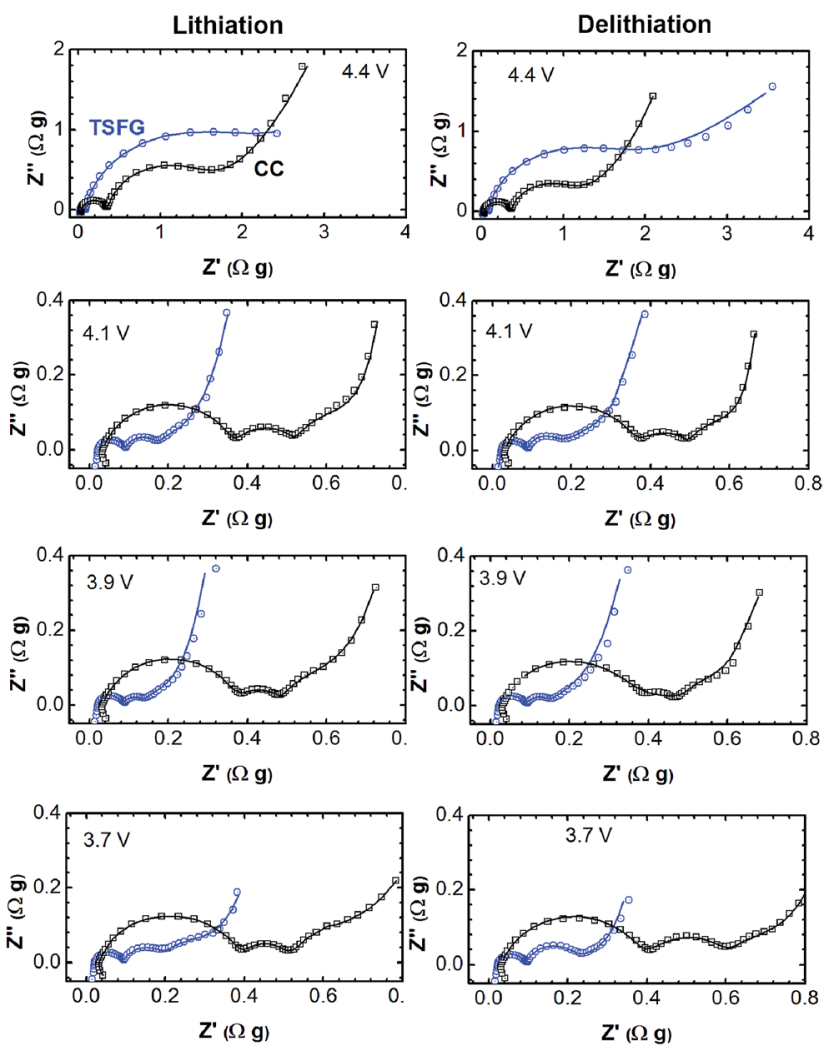

Fig. 6 Nyquist diagrams experimentally measured at different stages of lithiation (left column) and delithiation (right column) in TSFCG and CC positive electrodes. The experimental data are represented by points and the fitting with solid lines.

(TMOs) because of the rich surface chemistry in alkyl carbonate electrolyte solutions and $\mathrm{LiPF}_{6}$ salts. Due to the highly basic and nucleophilic character of the TMO oxygens, they react rapidly with acidic species $\left(\mathrm{HF}, \mathrm{PF}_{5}\right.$, and $\mathrm{PF}_{3} \mathrm{O}$ formed from the partial decomposition of $\mathrm{LiPF}_{6}$ and the reaction between $\mathrm{PF}_{5}$ and trace water) to produce $\mathrm{M}-\mathrm{O}-\mathrm{PO}_{x} \mathrm{~F}_{y}$ compounds. TMO oxygens also react with the electrophilic alkyl carbonate molecules to initiate polymerization reactions that form surface polycarbonate species. ${ }^{20}$ Also, the formation of the surface film through the reaction of $\mathrm{Li}_{x} \mathrm{MO}_{2}$ with $\mathrm{CO}_{2}$ has been demonstrated. ${ }^{21}$ The

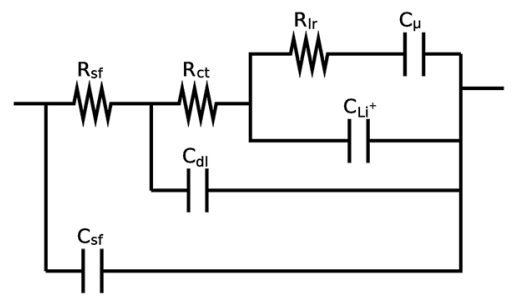

Fig. 7 Equivalent circuit used for fitting (i) resistance and capacity ascribed to the surface film layer, $R_{\mathrm{sf}}$ and $C_{\mathrm{sf}}$; (ii) the interfacial chargetransfer resistance, $R_{\mathrm{ct}}$, combined with the double-layer capacitance, $C_{\mathrm{dl}}$, that dominates the intermediate-frequency response; and (iii) reaction sub-circuit modeled by the chemical capacitance $C_{\mu}, \mathrm{Li}^{+}$ capacitance, $\mathrm{C}_{\mathrm{Li}}{ }^{+}$, and the lithiation-reaction resistance, $R_{\mathrm{lr}}$. 
second arc at intermediate-high frequencies shown in Fig. 6 is related to electrical processes occurring at the particle interface labeled as the charge-transfer resistance, $R_{\mathrm{ct}}$, and the double layer capacitance, $C_{\mathrm{dl}}$. At low frequencies, the Nyquist plots indicate the capacitive behavior associated with $\mathrm{Li}^{+}$ion storage inside the positive electrode. The chemical capacitance, $C_{\mu}$, in series with a resistance, $R_{\mathrm{l}}$, has been ascribed to different ratelimiting mechanisms. Traditionally, transport limitations have been related to solid-state diffusion of $\mathrm{Li}^{+}$inside the host material, particularly for intercalation compounds. ${ }^{22}$ More recently, other mechanisms accounting for the hindrance of resistive elements have been identified in electrochemical $\mathrm{Li}^{+}$ alloying and conversion in the oxide matrixes. ${ }^{17,23}$ The lack of clear Warburg-like patterns in the low-frequency response (Fig. 6) suggests a simple model comprising the series $R_{\mathrm{lr}}$ and $C_{\mu}$ connection. Therefore, the additional resistance at low frequencies accounts generically for $\mathrm{Li}^{+}$intake limitations irrespective of the underlying microscopic mechanism (ion diffusion and/or reaction). In the voltage range of 3.7-4.2 $\mathrm{V}$ (the plateau region in Fig. 3), an additional capacitive element is observed at low frequencies. This capacitance, $\mathrm{C}_{\mathrm{Li}}{ }^{+}$, accounts for the contribution of inserted $\mathrm{Li}^{+}$before reaching stable sites within the matrix. ${ }^{14}$ It is noted that $C_{\mathrm{Li}}{ }^{+}$produces a small arc at low frequencies before obtaining the true capacitance behavior.

The previously described equivalent circuit elements are connected as shown in Fig. 7. Each subcircuit accounts for the electrode response of a specific frequency range: $R_{\mathrm{sf}}$ and $C_{\mathrm{sf}}$ represent model surface film ion migration rapid mechanisms; $R_{\mathrm{ct}}$, and $C_{\mathrm{dl}}$ stand for intermediate frequencies capturing electrochemical processes at the active particle interface; and $C_{\mu}$, $C_{\mathrm{Li}}{ }^{+}$, and $R_{\mathrm{lr}}$ represent slow charging and reaction processes occurring inside the particles. Our model connects the lowfrequency subcircuit in series with the interfacial charge transfer resistance $R_{\mathrm{ct}}$ while putting $C_{\mathrm{dl}}$ in parallel. This circuit element connection agrees with the original Randles circuit accounting for the electrochemical impedance of surfaces.

Fig. 6 provides an overview of the electrochemical limitations in both positive electrodes. Over the whole voltage range, the first arc ascribed to the surface film is independent of the applied voltage and is higher for CC than TSFCG positive electrodes. The second arc (related to the charge transfer at the electrode interface) is dependent on the applied voltage and decreases within the voltage range, where the redox modifications occur. At low frequencies, the Nyquist plots of both electrodes show similar behaviors. These observations imply that the main differences in lithiation and delithiation processes occur at the electrode interface rather than inside the oxide host positive electrode.

The values of $C_{\mu}$ are provided in Fig. 8. This chemical capacitance is associated with the differential change in the electrode charge upon voltage variation ${ }^{24}$ and accounts for the ability of the oxide matrix to react with $\mathrm{Li}^{+}$ions. Chemical capacitance should show quasi-equilibrium (very low-frequency limit) behavior in the cyclic voltammetry experiment and theoretically corresponds to the derivative of the chargedischarge curve as $C_{\mu}=-\mathrm{d} Q / \mathrm{d} V$. This differential capacitance is also calculated from the measurements of charge-discharge $(V$

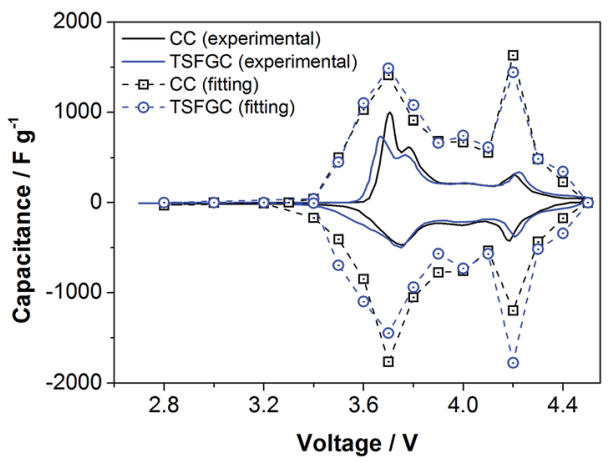

Fig. 8 Chemical capacitance of the CC and TSFCG electrodes obtained from $-\mathrm{d} Q / \mathrm{d} V$ of the charge/discharge measurements at $0.1 C$, and the $C_{\mu}$ calculated from the EIS data using the equivalent circuit.

vs. Q), as plotted in Fig. 8. The capacitances obtained from both methods show the typical shape of this material associated with the overall reaction $\mathrm{Li}_{x}\left(\mathrm{Ni}_{y}{ }^{2+} \mathrm{Co}_{z}{ }^{3+} \mathrm{Mn}_{1-y-z}{ }^{4+}\right) \mathrm{O}_{2} \leftrightarrow\left(\mathrm{Ni}^{4+} \mathrm{C}\right.$ $\left.\mathrm{O}^{4+} \mathrm{Mn}^{4+}\right) \mathrm{O}_{2}+x \mathrm{Li}^{+}+x \mathrm{e}^{-25,26}$ We notice that capacitance extracted from EIS measurements is always larger than that calculated from galvanostatic experiments. This discrepancy is related to the different experimental conditions; whereas EIS yields a very low-frequency limit (quasi steady-state) extrapolated from the actual measuring frequency window, the charge-discharge derivative method cannot be regarded as a steady-state measurement, even though a rate as slow as $0.1 \mathrm{C}$ is used for these measurements. Maxima upon lithiation and delithiation are present at the same voltage for both experimental methods. Notably, in dynamic measurements, such as cyclic voltammetry, the peak at $4.2 \mathrm{~V}$ is lower than that observed at $3.7 \mathrm{~V},,^{27-29}$ as it is obtained from the charge-discharge plot (see CV plots shown in Fig. SI. $1 \dagger)$. Nevertheless, the chemical capacitances obtained from EIS are slightly higher for the peak registered at $4.2 \mathrm{~V}$. This fact suggests that the process is kinetically rather than thermodynamically inhibited. The kinetic origin of the chemical capacitance reduction when extracted from the chargedischarge curve derivative will later be related to differences in $R_{\mathrm{lr}}$. The peak that appears at $3.7 \mathrm{~V}$ has been assigned to the change in the oxidation state of Ni upon lithiation, ${ }^{6,30}$ while the peak at $4.2 \mathrm{~V}$ has been ascribed either to the Co oxidation state change $^{30}$ or to an oxide phase transition. ${ }^{6,27}$

As observed in Fig. 8, similar values of the capacitive elements of both materials suggest that the two positive electrodes have practically the same thermodynamic behavior. This indicates that the difference in rate capability is related to variations in charge/discharge process kinetics. The fitting resistances of the different electrochemical steps in the positive electrode upon lithiation/delithiation processes are depicted in Fig. 9. These were extracted to evaluate the hindrance mechanism. All the resistances in the electrode are lower than $1 \Omega \mathrm{g}$ within the voltage range where the electrochemical processes develop (3.6-4.3 V). In all cases, the resistances in the TSFCG material are lower than those in the CC, which explains the superior rate capability of the TSFCG positive electrode. The processes related to the high-frequency EIS, ascribed to the 


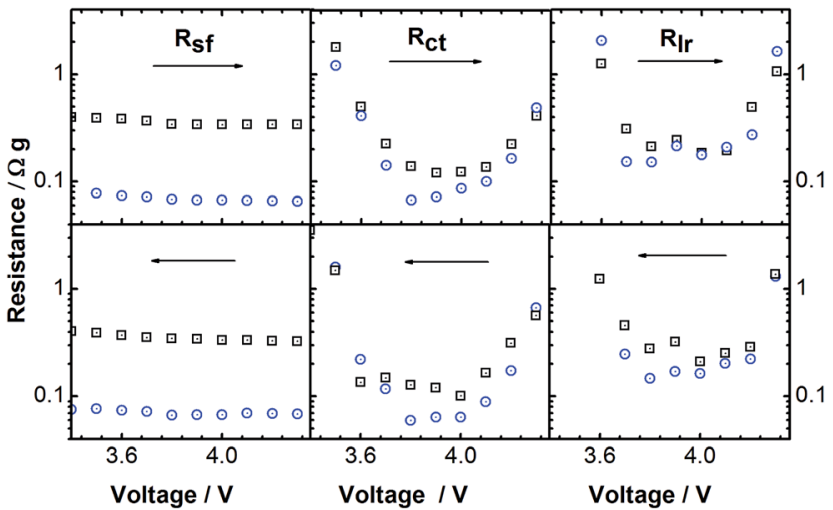

Fig. 9 Parameter fitting in the charge/discharge process: $R_{\mathrm{sf}}(\Omega \mathrm{g}), R_{\mathrm{ct}}$ $(\Omega \mathrm{g})$, and $R_{\mathrm{tr}}(\Omega \mathrm{g})$. Black squares represent the values of CC ( $\left.\square\right)$, and blue circles the values of the TSFCG (๔).

conduction processes at the electrode-electrolyte solid interface, exhibit a larger difference. The main difference is in the $R_{\mathrm{sf}}$ parameter, which suggests that a surface layer is formed to a lesser extent on the TSFCG positive electrode. Among the three transition metals, $\mathrm{Ni}$ has been reported to enhance the nucleophilicity of the oxygens, ${ }^{31}$ and it is more surface reactive than the other two species. ${ }^{32}$ In fact, $\mathrm{Li}_{x} \mathrm{NiO}_{2}$ is more reactive with standard electrolytes than are $\mathrm{Li}_{x} \mathrm{CoO}_{2}$ and $\mathrm{Li}_{x} \mathrm{MnO}_{2}$ compounds. ${ }^{20}$ In this regard, the TSFCG structure in which $\mathrm{Ni}$ cations are concentrated inside the particle should account for the lower reactivity of the TMO with the electrolyte solution compounds. Further, this lower reactivity should reduce the formation of the surface film in the TSFCG structure relative to the CC. $R_{\mathrm{ct}}$ values are also slightly lower in the TSFCG compared to $\mathrm{CC}$ in the delithiation process between 3.7 and $4.0 \mathrm{~V}$. This effect is probably a consequence of the special morphology of TSFCG electrodes (micrometer-sized spherical particles composed of nanometer-sized rod-shape structures aligned to the center) that favors fast $\mathrm{Li}^{+}$transfer between the electrolyte and the nanorods of the electrode. EIS allowed us to differentiate between the two interfacial electrochemical processes and to conclude that the main advantage of the TSFCG is its special structure. That is, the rich core of Ni provides high capacity, and the low Ni presence on the surface of the particle diminishes the reactivity with electrolytes, resulting in decreased surface film formation.

\section{Conclusions}

A nickel-rich lithium nickel-cobalt-manganese oxide $\left(\mathrm{Li}\left[\mathrm{Ni}_{0.8^{-}}\right.\right.$ $\left.\mathrm{Co}_{0.06} \mathrm{Mn}_{0.14}\right] \mathrm{O}_{2}$ ) positive electrode with a two-sloped full concentration gradient was successfully synthesized and characterized. Its electrochemical performances were compared with those of the CC Li[ $\left[\mathrm{Ni}_{0.8} \mathrm{Co}_{0.06} \mathrm{Mn}_{0.14}\right] \mathrm{O}_{2}$ positive electrode without a concentration gradient. In half-cell testing, the TSFCG $\mathrm{Li}\left[\mathrm{Ni}_{0.8} \mathrm{Co}_{0.06} \mathrm{Mn}_{0.14}\right] \mathrm{O}_{2}$ positive electrode showed outstanding cycle life with a capacity retention of $94.6 \%$ after 100 cycles, whereas the CC positive electrode suffered from a poor cycle life, delivering a capacity retention of only $79.2 \%$. EIS data enabled differentiation between the two interfacial electrochemical processes and showed that the low Ni concentration on the surface of the TSFCG particle diminishes the reactivity with the electrolytes, thus resulting in stable surface film formation.

\section{Acknowledgements}

This work was mainly supported by the Global Frontier R\&D Program (2013M3A6B1078875) of the Center for Hybrid Interface Materials (HIM) funded by the Ministry of Science, ICT \& Future Planning of Korea and National Research Foundation of Korea (NRF) grant funded by the Korea government (MEST) (No. 2014R1A2A1A13050479). Generalitat Valenciana (project ISIC/ 2012/008 Institute of Nanotechnologies for Clean Energies) is also acknowledged.

\section{References}

1 B. Scrosati and J. Garche, J. Power Sources, 2010, 195, 24192430.

2 N. S. Choi, Z. Chen, S. A. Freunberger, X. Ji, Y.-K. Sun, K. Amine, G. Yushin, L. F. Nazar, J. Cho and P. G. Bruce, Angew. Chem., Int. Ed., 2012, 51, 9994-10024.

3 K.-S. Lee, S.-T. Myung, K. Amine, H. Yashiro and Y.-K. Sun, J. Electrochem. Soc., 2007, 154, A971-A977.

4 L. Wang, J. Li, X. He, W. Pu, C. Wan and C. Jiang, J. Solid State Electrochem., 2009, 13, 1157-1164.

5 J. Molenda and A. Milewska, J. Power Sources, 2009, 194, 8892.

6 H.-J. Noh, S. Youn, C. S. Yoon and Y.-K. Sun, J. Power Sources, 2013, 233, 121-130.

7 Y. Kim, ACS Appl. Mater. Interfaces, 2012, 4, 2329-2333.

8 M.-H. Kim, H.-S. Shin, D. Shin and Y.-K. Sun, J. Power Sources, 2006, 159, 1328-1333.

9 J. Cho, T.-J. Kim, J. Kim, M. Noh and B. Park, J. Electrochem. Soc., 2004, 151, A1899-A1904.

10 Y.-K. Sun, Z. Chen, H.-J. Noh, D.-J. Lee, H.-G. Jung, Y. Ren, S. Wang, C. S. Yoon, S.-T. Myung and K. Amine, Nat. Mater., 2012, 11, 942-947.

11 H.-J. Noh, Z. Chen, C. S. Yoon, J. Lu, K. Amine and Y.-K. Sun, Chem. Mater., 2013, 25, 2109-2115.

12 H. J. Noh, J. W. Ju and Y. K. Sun, ChemSusChem, 2014, 7, 245252.

13 B.-B. Lim, S.-J. Yoon, K.-J. Park, C. S. Yoon, S.-J. Kim, J. J. Lee and Y.-K. Sun, Adv. Funct. Mater., 2015, 25, 4673-4680.

14 F. Martinez-Julian, A. Guerrero, M. Haro, J. Bisquert, D. Bresser, E. Paillard, S. Passerini and G. GarciaBelmonte, J. Phys. Chem. C, 2014, 118, 6069-6076.

15 C. Xu, Y. Zeng, X. Rui, J. Zhu, H. Tan, A. Guerrero, J. Toribio, J. Bisquert, G. Garcia-Belmonte and Q. Yan, J. Phys. Chem. C, 2013, 117, 17462-17469.

16 S.-J. Yoon, K.-J. Park, B.-B. Lim, C. S. Yoon and Y.-K. Sun, J. Electrochem. Soc., 2015, 161, A3059-A3063.

17 M. Haro, T. Song, A. Guerrero, L. Bertoluzzi, J. Bisquert, U. Paik and G. Garcia-Belmonte, Phys. Chem. Chem. Phys., 2014, 16, 17930-17935. 
18 Z. Li, F. Du, X. Bie, D. Zhang, Y. Cai, X. Cui, C. Wang, G. Chen and Y. Wei, J. Phys. Chem. C, 2010, 114, 22751-22757.

19 Y.-K. Sun, S.-T. Myung, C. S. Yoon and D.-W. Kim, Electrochem. Solid-State Lett., 2009, 12, A163-A166.

20 R. Marom, S. F. Amalraj, N. Leifer, D. Jacob and D. Aurbach, J. Mater. Chem., 2011, 21, 9938-9954.

21 O. Haik, N. Leifer, Z. Samuk-Fromovich, E. Zinigrad, B. Markovsky, L. Larush, Y. Goffer, G. Goobes and D. Aurbach, J. Electrochem. Soc., 2010, 157, A1099-A1107.

22 J. Song and M. Z. Bazant, J. Electrochem. Soc., 2013, 160, A15A24.

23 P. Acevedo-Peña, M. Haro, M. E. Rincón, J. Bisquert and G. Garcia-Belmonte, J. Power Sources, 2014, 268, 397-403.

24 J. Bisquert, Phys. Chem. Chem. Phys., 2003, 5, 5360-5364.

25 Y. Koyama, I. Tanaka, H. Adachi, Y. Makimura and T. Ohzuku, J. Power Sources, 2003, 119, 644-648.
26 M. G. Kim, H. J. Shin, J.-H. Kim, S.-H. Park and Y.-K. Sun, J. Electrochem. Soc., 2005, 152, A1320-A1328.

27 Y.-K. Sun, D.-H. Kim, H.-G. Jung, S.-T. Myung and K. Amine, Electrochim. Acta, 2010, 55, 8621-8627.

28 Y.-K. Sun, S.-T. Myung, B.-C. Park and K. Amine, Chem. Mater., 2006, 18, 5159-5163.

29 K. Shaju, G. Subba Rao and B. Chowdari, Electrochim. Acta, 2002, 48, 145-151.

30 B. Hwang, Y. Tsai, D. Carlier and G. Ceder, Chem. Mater., 2003, 15, 3676-3682.

31 S. Martha, E. Markevich, V. Burgel, G. Salitra, E. Zinigrad, B. Markovsky, H. Sclar, Z. Pramovich, O. Heik and D. Aurbach, J. Power Sources, 2009, 189, 288-296.

32 H. Sclar, D. Kovacheva, E. Zhecheva, R. Stoyanova, R. Lavi, G. Kimmel, J. Grinblat, O. Girshevitz, F. Amalraj and O. Haik, J. Electrochem. Soc., 2009, 156, A938-A948. 